\title{
Using Dynamic Constraints Find Top Products
}

\author{
Nihalahmad R. Shikalgar \\ Assistant Professor \\ Department of Computer \\ AITRC, Vita
}

\author{
Dhanaji Jadhav \\ Assistant Professor \\ Department of Computer \\ AITRC, Vita
}

\begin{abstract}
The growing popularity of online product review forums invites people to express opinions and purchase their products. In variety of different item set, it is very difficult to analysis skyline product from the set of different product. A consumer electronics world, product should consisting of varieties in color, functionality, applicability, reasonability, there look and all. It is unpredictable to select a product from pool of given product. In multi-criteria decision making application, most previous studies focus on how to help customers find a set of best possible , profitable products from a pool of given products. In this paper, we identify an interesting problem, using dynamic constraint find top $\mathrm{k}$ product, which has not been studied before.
\end{abstract}

Given a set of products in the existing market, we want to find a set of "best" possible products such that these new products are not dominated by the products in the existing market. A straightforward solution is to enumerate all possible subsets of size $\mathrm{k}$ and find the subset which gives the greatest profit. However, there are an exponential number of possible subsets. In this paper, we propose solutions to find the top-k products efficiently by considering. An extensive performance study using both synthetic and real datasets is reported to verify its effectiveness and efficiency.

\section{Keywords}

Text mining.

\section{INTRODUCTION}

Dominance analysis is important in many multi-criteria decision making applications. A package which is not dominated by any other packages is said to be a skyline package or it is in the skyline [1]. Recently skyline analysis has received a lot of interest in the literature. In the existing system it is difficult to find the profitable products [2] in the existing market. They are doing these by comparing the same type of product with each other. But, it is very complicated and time consuming process. Most of the work included in the existing system is manual. So because of these manual works lot of efforts are taken by the users. Although most of the companies had already developed their website the user was not easily able to understand to use this web application .When there was need add some data in database then the whole database was changed [9]. There is lot of transaction done every day in the moll so there is need to update data dynamically. So this work is done manually in the existing system. Because in the existing system the data was not added dynamically .This was all the challenges which were included in the existing system.

Complexities are more in the existing system. Customers have to take information of all products. Consider different attribute, qualities, price, and validity of it. It is very time consuming process. Sometimes these attribute also not sufficient for customer means user should not satisfied with these attribute. He / She should know about user experience of using these products. So in today's world number of web forums invite people to express their opinion of product. Need to maintain all the record. It is very difficult to implement on the dynamic data. More paper work is included. Price prediction is very difficult. Finding the top-k profitable product means we are finding the best product from the market by considering the user recommendation. Today this system is implemented many of times in the market. In every travel agency this system is implemented. There are many packages provided by the travel agency to the customer [1]. At that time they need to set the price of the new package. So with the help of this system they can set the price of the new package easily. www.expedia.com is one of the good examples which is using this system. Today mobile phone companies are launching new product day by day. So while setting the price of the new package they are using this system. The companies can maintain all the record of selling and purchasing with the help of database included in it. The priceline.com is one another good example of it. In most of the big molls there is huge data that is to be maintained, so with the help of this database they can maintain the data. There is need to update the data every day, so to do this task manually is more difficult, so they can update these data with the help of this web application. The user can know the best possible product with the help of this web application.

In the proposed system we are developing the online web application to reduce the efforts of the companies. The user and manufacturer can use this web application for different purposes and the administrator can control this web application. This web application can login by the user, manufacturer and administrator. When the user will access this web application then the homepage will be displayed. They can compare the products of different companies [4]. This way they can easily get the best product. After that they can give rating or proper review to the products [6].

Administrator controls the whole website i.e. it will decide which options should be provided to the user. Administrator will access user reviews can do changes according to the user. Administrator decides which option should be viewed to the user. Administrator can change the database dynamically and can make changes according to need. It will be easy to maintain records and documents in the database.

Our proposed system contribute with following,

- $\quad$ Reduces efforts of the companies.

- $\quad$ Easy to make multi-criteria based decision.

- $\quad$ Easy to add the data dynamically.

- Easier access to Information.

- Improved efficiency and effectiveness.

- More reliable security for sensitive and confidential information. 
- Improved customer service through greater access to accurate information.

\section{RELATED WORK}

Driven by many recent applications such as environmental surveillance, market analysis, quantitative economics research, WWW, and large sensor networks, a rapidly growing amount of research has been dedicated to managing uncertain data. Uncertainty is inherent in such applications because of various factors including data randomness and incompleteness, limitations of measuring equipment's, delayed data updates etc.

As the variety of products are increasing day by day, So today many companies need to make multi-criteria decision [8] many of the times. Today many of the new products is been launched in the market, so it becomes difficult to set the price of this new products. It can set the prices of these products such that we can obtain the maximum profit. Finding top-k profitable products is common in many real life applications. Other applications include finding profitable laptops in a new laptop company, finding profitable delivery services in a new cargo delivery company and finding profitable eadvertisements in a webpage.

Skyline analysis [1] has been demonstrated very useful in multi-criteria decision making applications. The skyline operation is useful for extracting interesting information from multidimensional databases [9]. This is done by comparing products within the different databases with each another. In an experimentation of skyline analysis, we consider the example of computer model. A proposed system reduces efforts of the companies. Easy to make multi-criteria based decision. It is easy to add the data dynamically also it is easier access to information. It will improve efficiency and effectiveness. It will provide more reliable security for sensitive and confidential information and improved customer service through greater access to accurate information.

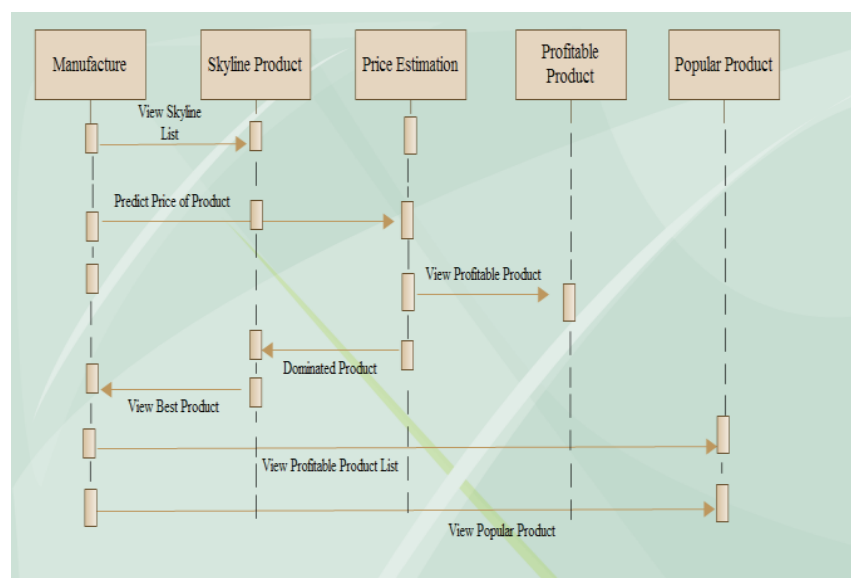

Figure 1. Sequence flow of system

Figure 1 show that sequence flow of proposed system. Manufacturer analyze skyline product [7]. If he/she wants to launch new product then necessary thing is that decide price. Price should be near about skyline so that there market selling value should increase. Consequently new launched product gives maximum profit.

\section{SKYLINE ANALYSIS}

In the first model we are collecting existing raw database, from that raw database we are generating one list known as skyline list [6]. This skyline list will be generated with the help of product attributes. In the first model we are collecting existing raw database, from that raw database we are generating one list known as skyline list. This skyline list will be generated with the help of product attributes.

Input:

We are taking raw data from the market. This raw data can be gained from different company's database. Another way to obtain this data is from the online social network sites.

\section{Processing:}

In the processing section, comparing of products is been occurred with the help of attributes. After that the Skyline list is generated from the existing raw database.

\section{Output:}

Hence, the skyline list will be generated from the existing raw database. From this it will be easy to obtain Best possible products.

\section{Price Estimation:}

In another part of model we set or predict price of new products which is launched in the market. This can be done from the user reviews and administrator can predict the price from the database also.

\section{Introduction:}

In another part of model we set or predict price of new products which is launched in the market. This can be done from the user reviews and administrator can predict the price from the database also.

\section{Input:}

Here the input for this model is prices of the most profitable products. And also the reviews of the user are also considered this time.

\section{Processing:}

In the process of the fourth model consider prices of profitable products and the user reviews and from that we can determine the prices of new products.

Output:

Thus we can set the prices of new products which are to be launched in the market.

\section{Profitable products}

In another part of model we determine the profitable product from the database. In this the administrator can see which the profitable product. The Manufacturer knows the profitable product after the price estimation.

\section{Introduction:}

In another part of model we determine the profitable product from the database. In this the administrator can see which the profitable product. The Manufacturer knows the profitable product after the price estimation. 
Input:

In this, the skyline list generated previously will be taken as an input. And also the new product with their attribute is also taken by the administrator. Data which is maintained in the database is being recognized.

\section{Processing:}

In the process we consider list of the product which we are having in the database. After that we are applying the optimal price prediction algorithm to find out the profitable product.

\section{Output:}

Thus we can display most profitable products from the available products in the database.

\section{Popular Products}

In another part of this system we consider the user recommendation and then the reviews given by the users. From that it will be easy to administrator to interact with the user.

\section{Rating Products}

In that part user rated the product on basis of different services .

\section{Introduction:}

In another part of this system we consider the user recommendation and then the reviews given by the users. From that it will be easy to administrator to interact with the user.

\section{Input:}

Here the user will provide the rating and the reviews. That will be considering as the input of this model.

\section{Processing:}

In this process the rating and the reviews provided by the user are being considered and maintained in the database. After required changes is being made accessing the database.

\section{Output:}

Thus we take the rating and the review from the database and make changes according to them.

\section{EXPERIMENTAL RESULTS}

The experimental analysis shows that system can accurately analyze profitable and popular product.It can solve problem of not only consumer but also the manufacturer. Consumer condidered with the selection of reasonable product and manufacturer considered with price estimations of new launching product. Estimated price of new product is an skyline product.

\begin{tabular}{|l||l||}
\hline Brand ID: & 7 \\
\hline Brand Name: & SowY \\
\hline Brand Service Centers & 6 \\
\hline Brand Rate & 5 \\
\hline & Sane \\
\hline
\end{tabular}

Figure 2 New Brand Entry
Figure 2 shows that new brand entry. This is new launching item where we can decide price for this. We can find skyline price consider to price of current item in the market which is of similar categories.

\begin{tabular}{|c|c|c|c|c|c|c|c|}
\hline Wung & Ext & Exayn & 橗 & 旺 & MEra? & Bats & 108 \\
\hline 1 & ลและ & is & 16 & 谓 & II & 墑 & 11 \\
\hline$i$ & สแพ4I & 4 & i咸 & 镭 & In & 䊼 & 17 \\
\hline 1 & MUAS & i & 16 & 罳 & 10 in & 㜖 & 1 \\
\hline 4 & H⿻上从 & II & 34 & 检 & It wh & 標 & 1 \\
\hline 1 & VIEANG & (1) & 16 & 畄 & Wh & 监 & 1 \\
\hline 1 & vThotil & 4 & 34 & m & Wnit & $m$ & $i$ \\
\hline 1 & W"WW4 & 4 & i6 & 櫺 & Whith & 㽦 & 1 \\
\hline 4 & स4-4ม & 4 & 34 & W & Minh & Ww & 1 \\
\hline
\end{tabular}

Figure 3 Top products

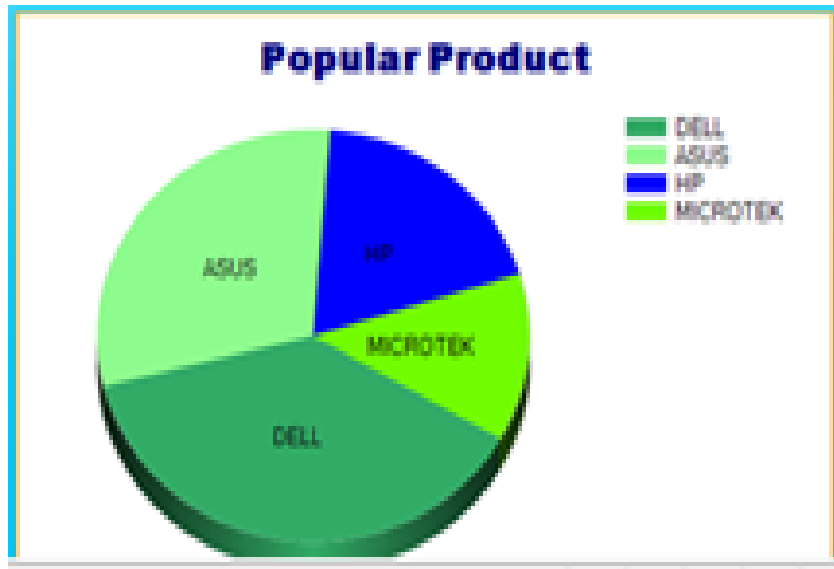

Figure 4 Popular products

Figure 3 shows that list of products with consider to associate attribute. Figure 4 shows that popular product from whole products .It showing how's growing popularity product have it. Figure 5 shows that top product with considering different attribute comparison. We here consider model id, brand id, model processor, model RAM, model HDD, model price.

\begin{tabular}{|c|c|c|c|c|c|c|c|}
\hline Medelis & Bnadid & Model Procenor & iscoldiray & 1 MladelinoD & Modil Scren Slate & Model Prike & Mldel Nunket \\
\hline 6 & 4 & D & $20 \mathrm{f}$ & 900 & 1Sind & 2000 & MTEKT:III \\
\hline 1 & 4 & b & 468 & 300 & 15 inth & 2000 & MTEK-AWA2 \\
\hline 8 & e & B & 208 & 780 & $15 \mathrm{ind}$ & 30000 & SAMSSD.1234 \\
\hline 1 & 1 & B & 208 & 1000 & 15 inch & 39000 & DELL.SZ12] \\
\hline ) & 5 & D & $40 \mathrm{fl}$ & 1000 & 15 inch & 13000 & SoNY.WWAS \\
\hline
\end{tabular}

Figure 5 Top products from attribute selection

\section{PRACTICAL IMPACT OF PROPOSED SYSTEM}

The product family approach, the level of product standardization versus product variety presents a trade-off scenario as product performance and appeal (from the customer's perspective) may diminish in an attempt to increase product standardization. This system is very much reliable on the synchronization working of the software and the hardware. If all components are in perfect state then result is accurate. This system is easily available in all areas. Just Corporation has to Employee some technician for adopting this system and has to bring some hardware and software which is needed for this system. This system is very secure 
because we can provide protection to software by only authorized people can use it.

This system requires less maintenance. All this setup is ones a fixed then we has to only analyze the result. In any case it is relatively very easy to use and maintain the system. As this system is very easy to use for the customer hence it is also an portable system

\section{CONCLUSIONS}

In this paper, we identify and tackle the problem of finding top-k products, which has not been studied before. We study two instances of preferable products, namely profitable products and preferable products. We propose methods to find top-k profitable products and top-k preferable products efficiently. An extensive performance study using both synthetic and real data sets is reported to verify its effectiveness and efficiency. As future work, we will study other instances of the problem of finding top-k preferable products by setting the utility function to other meaningful objective functions. One promising utility function is the function which returns the sum of the unit profits of the selected products multiplied by the number of customers interested in these products.

\section{REFERENCES}

[1] Q. Wan, R. C.W. Wong, and Y. Peng, "Creating top-k profitable products", http://www.cse.ust.hk/ raywong/ paper /createTopKProfitableProducttechnical.pdf.
[2] Q. Wan, R.C.-W. Wong, and Y. Peng, "Finding Top-K Profitable Products", Proc. Int'l Conf. Data Eng. (ICDE), 2011.

[3] N. Archak, A. Ghose, and P.G. Ipeirotis, "Show Me the Money: Deriving the Pricing Power of Product Features by Mining Consumer Reviews", Proc. 13th ACM SIGKDD Int'l Conf. Knowledge Discovery and Data Mining (KDD ’07), pp. 56-65, 2007.

[4] Q. Wan, R. C.W. Wong, I. F. Ilyas, M. T. Ozsu, and Y. Peng, "Creating competitive products", In VLDB 2009.

[5] O.B.N. et al, "On the distribution of the number of admissible points in a vector random sample", In Theory of Probability and its Application, 11(2), 1966.

[6] B. Jiang, J. Pei, X. Lin, Cheung, and J. Han, "Mining preferences from superior and inferior examples", In SIGKDD, 2008.

[7] D. Kossmann, F. Ramsak, and S. Rost, "Shooting stars in the sky: An online algorithm for skyline queries", In VLDB, 2002.

[8] X. Lin, Y. Yuan, Q. Zhang, and Y. Zhang, "Selecting stars: the k most representative skyline operator", In ICDE, 2007.

[9] D. Papadias, Y. Tao, G. Fu, and B. Seeger, "Progressive skyline computation in database systems", In ACM Transactions on Database Systems, Vol. 30, No. 1, 2005. 